\title{
THE SURFACE TENSION OF THE BLOOD SERUM IN NEPHRITIS
}

\author{
BY LOUIS LEITER \\ (From the Hospital of the Rockefeller Institute for Medical Research, New York)
}

(Received for publication July 16, 1926)

This study had as its aim the collection of data on the surface tension of the serum in the various types of renal disease, and the correlation of these with other manifestations of the disease. The problem of edema was the focus of interest. On the one hand, low surface tension has been connected etiologically with edema by Clausen (1), who isolated from the urine a surface-active substance capable of altering the permeability of collodion membranes to protein solutions. It appeared that at least one factor in edema formation might be altered permeability of the capillaries due to this surface active substance. On the other hand the clear-cut work of Govaerts (2) shows a constant relationship between nephritic edema and a lowered osmotic pressure of the plasma colloids, due to the low albumin content. We have, therefore, studied nephritic edema from the point of view of its relation to surface tension on the one hand, and to the plasma proteins, more particularly the plasma albumin, on the other.

There is in the literature a fair amount of data concerning surface tension in health and disease, most of the values having been obtained by means of the Traube stalagmometer. Kisch and Remertz (3) observed the relatively low values in the case of cloudy or milky sera and those colored by hemoglobin. They found that the cerebrospinal fluid has practically the same surface tension as distilled water, and ascribed this to the low concentration of colloids in it. Traube (4) included a series of nephritic cases in his tables on surface tension of the blood serum in various diseases. It is interesting, in view of the work of Clausen (5), to note that Traube had low values for some of the nephritic sera which were also cloudy or milky. Clausen (5) has recently published data on a considerable series of normal subjects and patients with nephritis. He found a distinct lowering of surface 
tension, as determined by the drop-weight method, in those patients with so-called parenchymatous nephritis or with nephrosis. There was some correlation between the low surface tension, the low plasma protein level, the high degree of albuminuria, and the presence of edema.

In the present study are included patients with different types of nephritis. The surface tension was determined on undiluted serum and on serum diluted 100 times with 0.9 per cent $\mathrm{NaCl}$ solution. In addition, the time curve of the fall in surface tension that occurs in serum standing quietly, described by duNoüy (6), was followed in about half of the cases studied.

\section{METHOD OF PROCEDURE}

The instrument used for the determinations was the original, indirect-reading tensiometer of duNoüy (7). The time-change measurements were made with the aid of the special table and the carriage on rollers for the tensiometer (8), kindly loaned to us by Dr. duNoüy. The watch-glasses were $5 \mathrm{~cm}$. in diameter and of standard curvature and depth. Two cubic centimeters of fluid were used. All the glassware, except the syringes for drawing blood, was boiled in potassium dichromate-sulphuric acid cleaning mixture, rinsed in distilled water and allowed to dry. The watch-glasses were not touched by the hands and were always flamed prior to using.

Blood was usually drawn from one to three hours after breakfast. It was allowed to clot and was centrifuged to separate the serum, which was pipetted off and kept at room temperature until used. Dilutions of serum were made with 0.9 per cent sodium chloride. The actual measurements were always begun within 4 or 5 hours from the time the blood was drawn. They were done at a room temperature of from $21^{\circ}$ to $24^{\circ} \mathrm{C}$. Except in the case of undiluted sera, all but a few of the determinations were repeated one or more times. The readings usually agreed within one per cent. The value obtained for distilled water at $23^{\circ} \mathrm{C}$. was 78.2 dynes per centimeter.

\section{DISCUSSION OF RESULTS}

The material studied included seven cases of active or convalescent acute nephritis, nine cases of chronic nephritis with varying degrees 
of impairment of renal function, three cases of chronic lipoid nephrosis, and one case which began apparently as nephrosis but later developed typical findings of chronic nephritis with renal insufficiency. All but one of these patients (case 16) had edema to a varying extent at one time or another during the course of the disease. The tables indicate the state of edema during the period when the surface tension measurements were made. The absence of edema may mean either that the patient was free from any tendency to edema or, more frequently, that the salt-free diet and rest in bed prevented the development of edema. The plasma protein figures were for the most part obtained from blood drawn a number of days before or after the surface tension determinations with which they are listed in the tables. However, the relative constancy of the plasma protein level in these patients justifies the use of the data for comparative purposes. The blood pressure figures represent averages of several determinations taken a few days before and after the surface tension measurements. The urea concentration index figures were obtained on the dates when they are listed or within a day or two of these dates. The manner of calculating the index has been described in a previous paper from this laboratory (9). The gross appearance of the serum has been characterized by the terms "clear," "slightly opalescent," "opalescent," "milky" and "creamy," in the order of increasing turbidity.

Most of the surface tension values were obtained on serum diluted 100 times with 0.9 per cent sodium chloride solution. It was found that such figures varied in the same direction as those of undiluted serum. Furthermore, instead of requiring $4 \mathrm{cc}$. of serum for duplicate determinations, $0.5 \mathrm{cc}$. was sufficient. Finally, the actual readings could be carried out more simply and accurately upon the diluted than upon the whole serum, because the surface tension does not fall so rapidly in the case of the former. The values for serum diluted a hundred-fold averaged 6.1 dynes higher than those for whole serum, the minimum difference being 4.5 dynes and the maximum 8.8 dynes.

Acute nephritis. In this series of seven cases, only case 2 still had marked impairment of renal function when the surface tension was determined. The rest were either convalescing or showing a tendency to go into a mild chronic state with little or no impairment of renal function. 


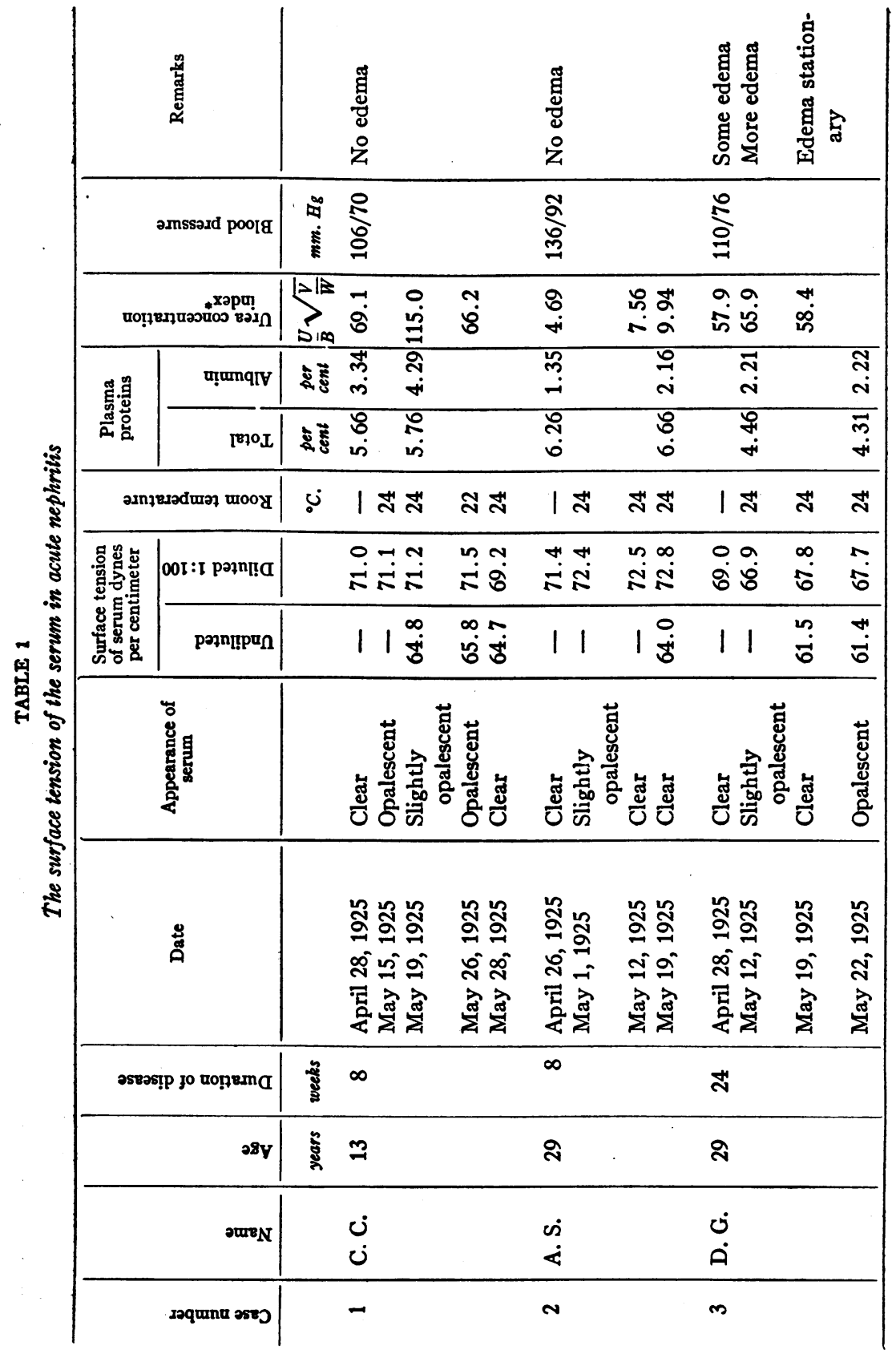




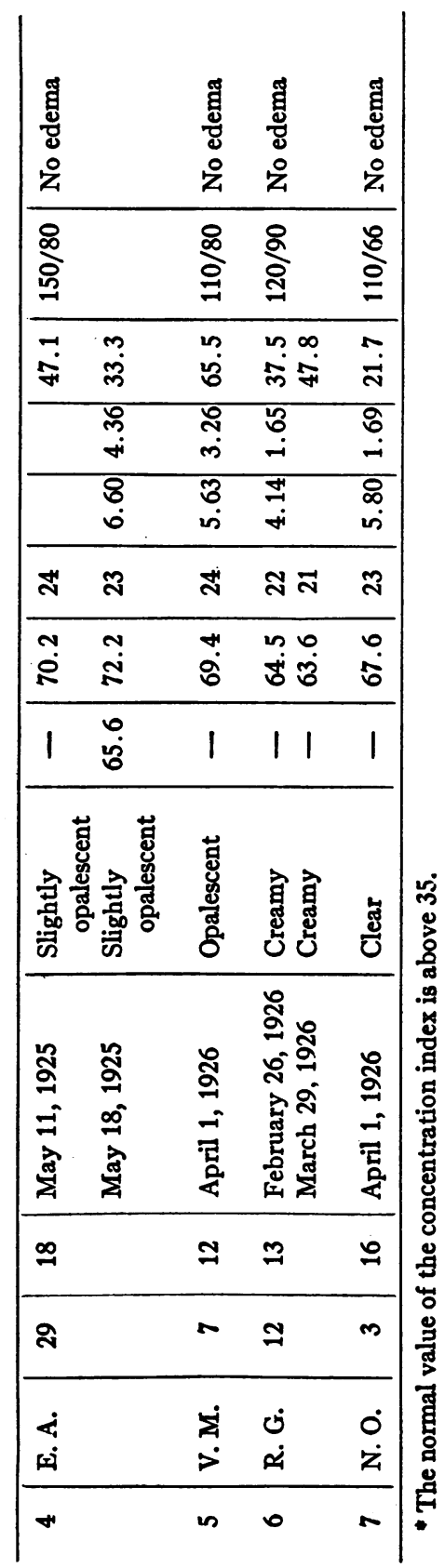


Certain relationships are apparent from table 1 and chart 1 . Cases $1,2,4$ and 5 form a group characterized by normal surface tension (64.0 to 65.8 dynes for undiluted serum and 69.2 to 72.8 dynes for serum diluted 1 to 100 ), by relatively clear sera, slightly lowered or normal plasma proteins and no edema. Cases 3 and 7 form an intermediate group with somewhat lower surface tension. Case 6 presents a

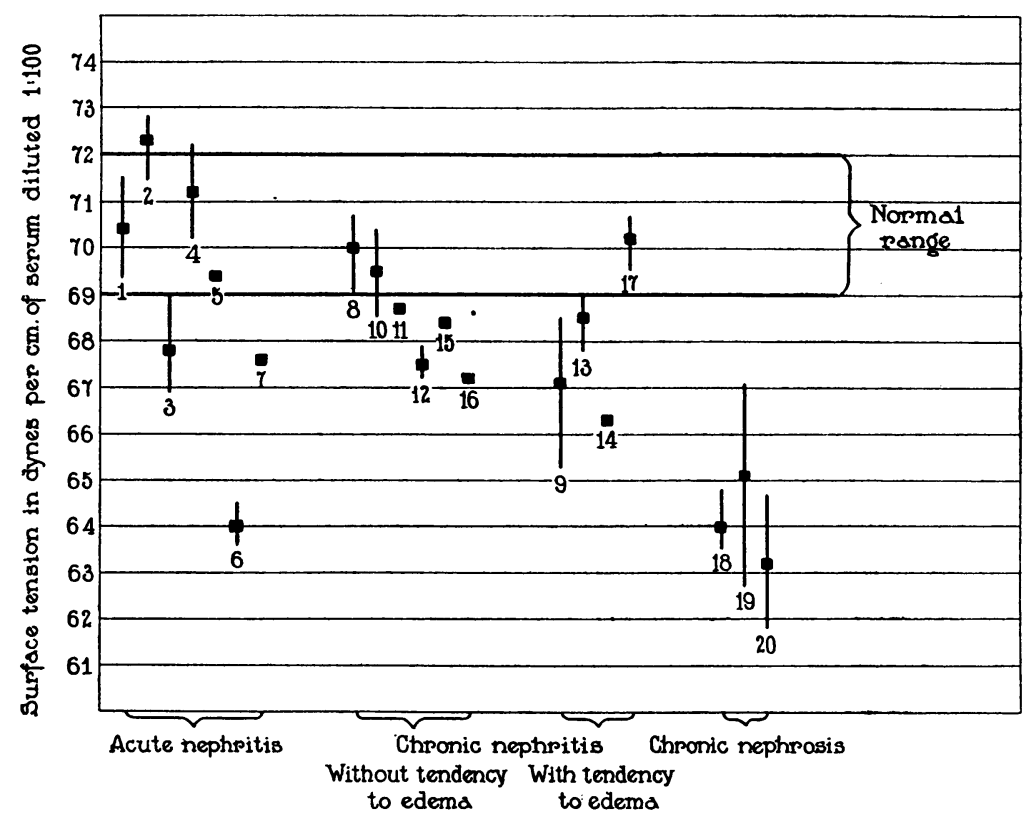

Chart 1. The vertical lines indicate the range of the surface tension values for each case, the solid squares represent the averages, the figures below the lines are the case numbers. Where only a square is shown, only one determination was made.

striking contrast because of its very low surface tension ( 64.0 dynes for 1:100 serum), the creamy appearance of the serum, and plasma proteins at a concentration of 4.14 per cent. There was temporary absence of edema on a salt-free regime, but edema recurred whenever the smallest amount of salt was added to the diet. In this child there has been a chronic mastoid infection for years to which the nephritis appears to have been secondary. However, this is definitely not a 
case of pure nephrosis, because microscopic hematuria persisted and there have been periods of impaired renal function.

Chronic nephritis. It is difficult to divide this series (table 2, chart 1), into groups like those of the preceding series, because considerable overlapping occurs. Cases 8 and 10 have normal surface tension values, clear sera, moderately diminished plasma proteins, and no edema. Cases 9, 11, 12, 13 and 14, form a motley group, the first and last showing much edema and fluid in the serous cavities, while the other cases were free from edema. All degrees of renal functional impairment were represented. The surface tension varied extensively both in the group and in the individual cases. No correlation could be made out between the surface tension and the level of plasma proteins. Case 13 showed the exceptional occurrence of a milky or creamy serum with almost normal surface tension. This was the only case with this combination and no explanation can be offered. Case 15 , a diabetic with chronic nephritis, and case 16, a gouty patient with chronic nephritis, are grouped together because they showed the unusual combination of relatively high plasma protein figures and moderately lowered surface tension, without edema. Case 17 was originally diagnosed as chronic nephrosis, but later developed the typical features of chronic nephritis. This patient had clear serum, which is an unusual finding in a case of nephrosis. She furnished the most interesting exception of all, normal surface tension in the presence of non-cardiac edema and extremely low plasma protein values.

While usually a tendency to edema, low plasma albumin content, and high plasma fat content are associated with lowered surface tension, combinations occur which are strikingly at variance with the assumption that these features occur consistently together. We have observed creamy serum with but slightly subnormal surface tension, high plasma proteins with abnormally low surface tension, very low proteins and normal surface tension, and considerable edema or tendency to edema with normal surface tension.

Chronic lipoid nephrosis. The three cases in this series (table 3, chart 1) fall naturally into one group, marked by milky or creamy sera, varying amounts of edema and fluid in the serous cavities, low plasma protein concentrations and consistently low surface tension. Yet the 


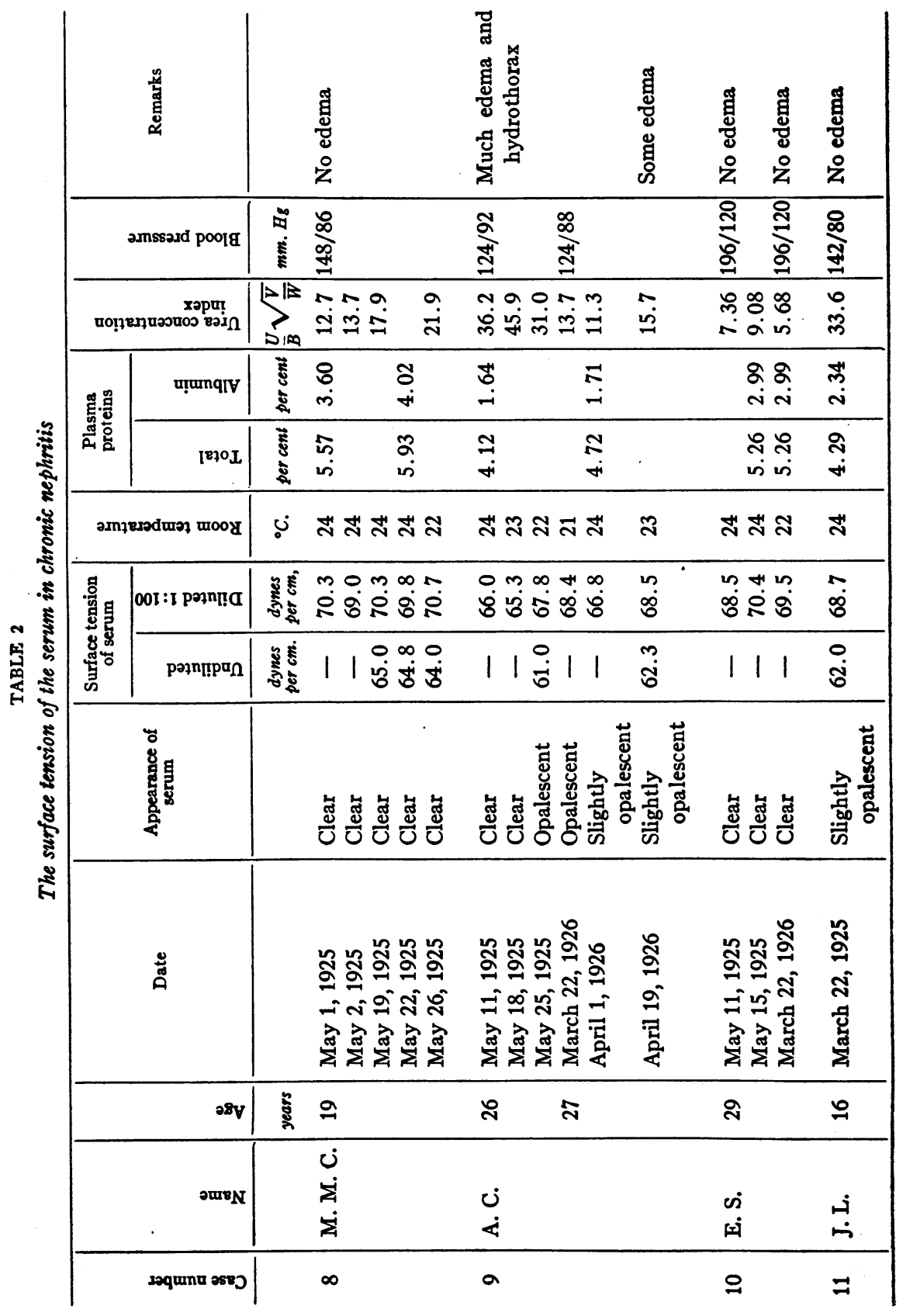




\begin{tabular}{|c|c|c|c|c|c|}
\hline 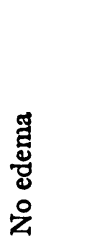 & 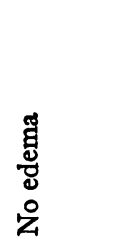 & 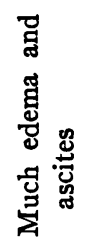 & 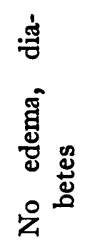 & 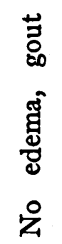 & 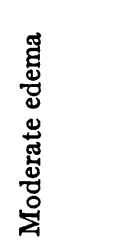 \\
\hline$\underset{ }{\mathbb{Z}}$ & $\stackrel{\infty}{\stackrel{\infty}{*}}$ & $\stackrel{\infty}{\infty}$ & ث্ণ & 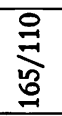 & 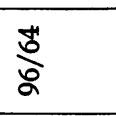 \\
\hline 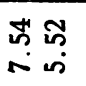 & $\begin{array}{l}n+9 \\
= \pm 9\end{array}$ & $\hat{\text { กิ }}$ & $\begin{array}{l}\$ \\
a\end{array}$ & $\stackrel{m}{=}$ & 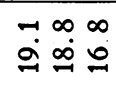 \\
\hline m & $\underset{\sim}{\sim}$ & $\stackrel{+}{-}$ & mे & $\begin{array}{l}8 \\
\dot{m}\end{array}$ & $\stackrel{\leftrightarrow}{\stackrel{\infty}{-}} \stackrel{\circ}{-}$ \\
\hline $\begin{array}{l}\Rightarrow \\
\text { in }\end{array}$ & $\stackrel{m}{+}$ & $\stackrel{0}{+}$ & î & $\stackrel{n}{-1}$ & 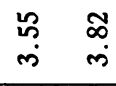 \\
\hline$\tilde{N} \tilde{N}$ & สี ส & $\ddot{\sim}$ & $\ddot{n}$ & 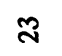 & | $\approx \pi$ \\
\hline $\begin{array}{l}\text { กิด } \\
\text { กิ์ }\end{array}$ & 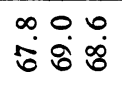 & $\ddot{8}$ & $\ddot{H}$ & $\stackrel{1}{0}$ & ñ் \\
\hline 11 & 111 & 1 & 1 & 1 & $1 \stackrel{00}{\text { ț }}$ \\
\hline 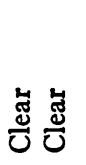 & 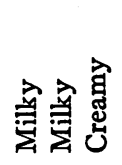 & $\frac{\mathrm{d}}{0}$ & 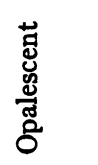 & ङ્ّ & 总怘岕 \\
\hline 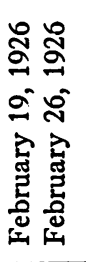 & 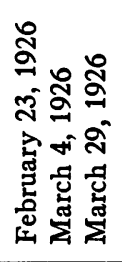 & 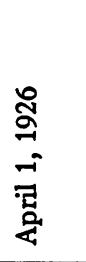 & 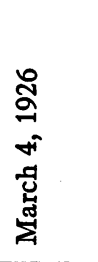 & 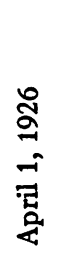 & 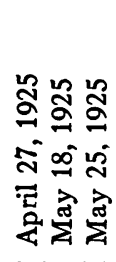 \\
\hline$\stackrel{\infty}{\sim}$ & ฉัง & $\nexists$ & ஜ & $\hat{m}$ & $\ddot{\sim}$ \\
\hline $\begin{array}{l}\dot{0} \\
\dot{0}\end{array}$ & $\dot{~}$ & ن & $\begin{array}{l}\dot{0} \\
\dot{\Sigma}\end{array}$ & $\dot{B}$ & $\dot{\varphi}$ \\
\hline$\cong$ & 2 & $\Xi$ & 20 & 으 & $\stackrel{*}{\Xi}$ \\
\hline
\end{tabular}




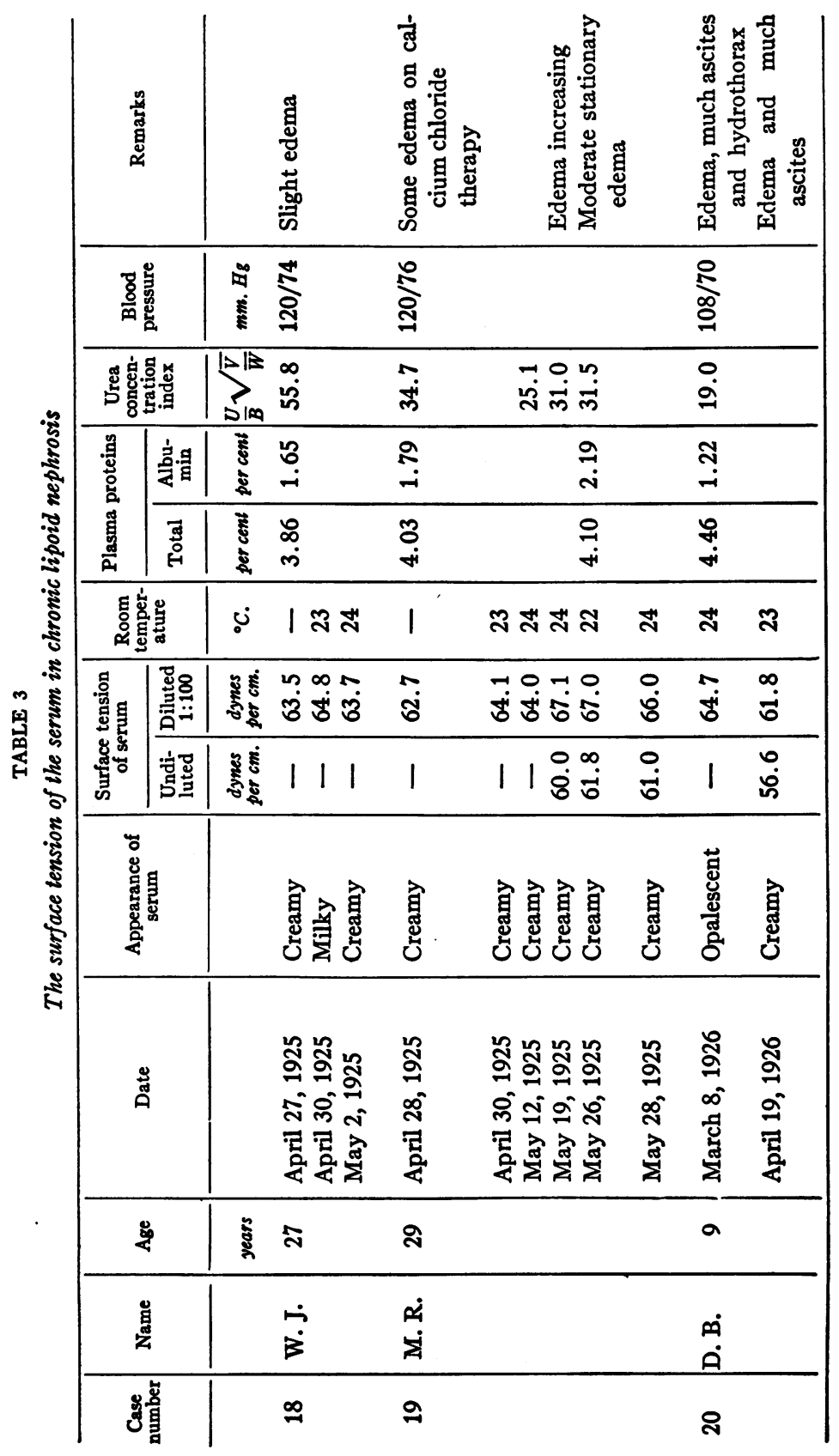


presence of all four features does not necessarily denote a pure lipoid nephrosis; e.g., case 6 in table 1.

The time-drop phenomenon of serum in renal disease. DuNoüy (6) found that when serum was allowed to stand exposed to air and the surface tension was measured at intervals, a distinct fall occurred. The explanation for this spontaneous fall in surface tension lies in the accumulation of surface-active substances, as a function of time, at the surface layer of the liquid, and in the possible formation of new surface-active material from substances present in the serum. A similar phenomenon occurs in aqueous solutions of sodium oleate and other organic substances. The fall amounted to only a few dynes in the case of undiluted serum, but to as much as 10 to 15 dynes or more when the serum was highly diluted, for example 1:10,000. The fall in surface tension begins as soon as the surface has been formed, is very rapid in the first few minutes, is almost completed within 20 minutes and reaches an equilibrium at the end of two hours. If the surface of the liquid is then disturbed, as by stirring, the surface tension rises again, to be followed by another time-drop. The extent of the difference between the initial value of the surface tension and that at the end of two hours varies with the dilution of the serum. The time-drop increases with increasing dilution until an optimum dilution is reached, and then diminishes progressively with increasing dilution.

In this work the sera were diluted with 0.9 per cent $\mathrm{NaCl}, 1: 100$, $1: 1,000,1: 5,000$ and 1:10,000. The surface tension was measured at once and at the end of two hours, the liquid being left undisturbed during the interval. The difference between the two readings constitutes the time-drop. The maximum time-drop occurred usually at a dilution of $1: 5,000$ or $1: 1,000$.

Table 4 shows the results obtained on different sera in the various types of renal disease. The great variation in the results, even for the same individual, contrasts with the relatively constant figures for surface tension in the preceding tables. There is also an entire lack of any outstanding difference between the values for one type of renal disease and those for another. It is true that the sera with low initial surface tension, as in cases $9,11,18$ and 19 , tend to have greater time-drop values in the various dilutions than the sera with normal initial surface tensions; but a single determination may fail to show this, 


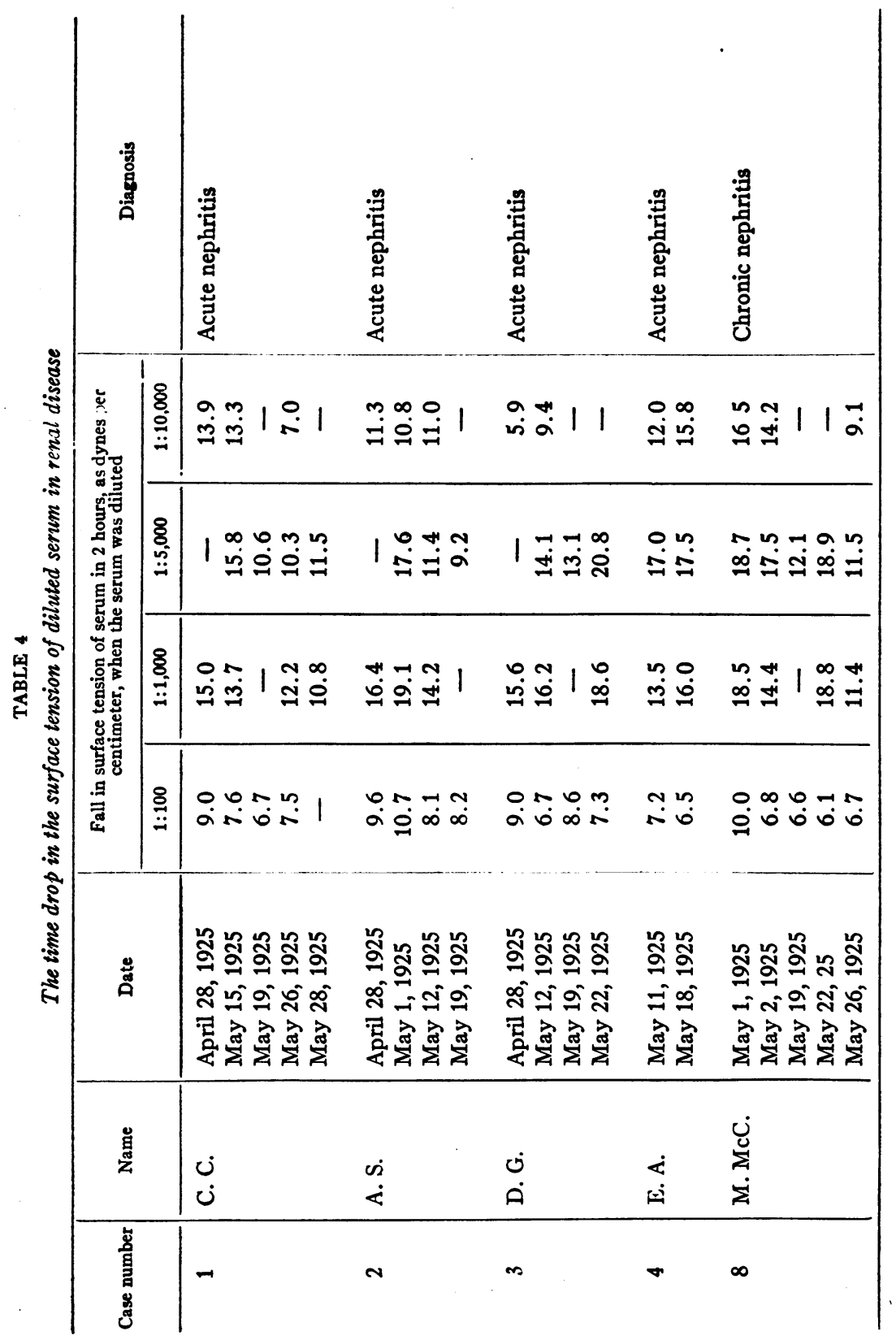




\begin{tabular}{|c|c|c|c|c|c|}
\hline 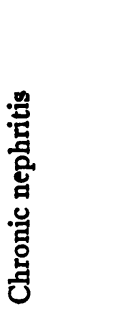 & 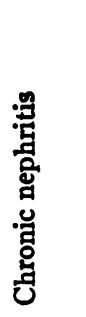 & 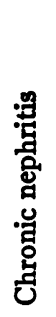 & 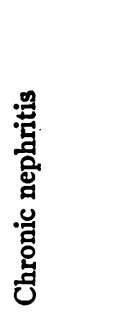 & 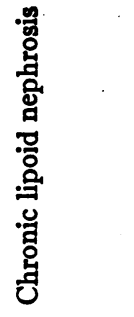 & 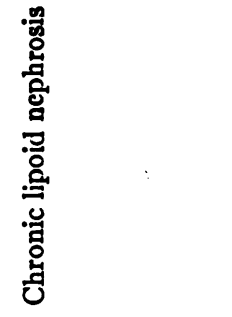 \\
\hline $\begin{array}{l}0 \infty \\
\dot{m} \stackrel{\infty}{\infty}=\dot{\infty}\end{array}$ & $\stackrel{0}{\vec{m}} \overrightarrow{\dot{H}}$ & 1 & تُ & $1 \stackrel{\infty}{\infty}$ & 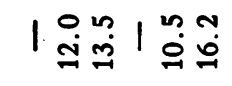 \\
\hline 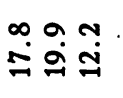 & $\Rightarrow 0$ & 这 & $\stackrel{\infty}{\Rightarrow} \hat{a} \infty$ & 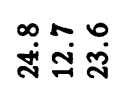 & 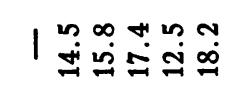 \\
\hline ma & $\ddot{n}$ & $\ddot{a}$ & 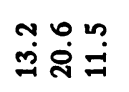 & 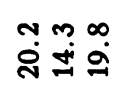 & 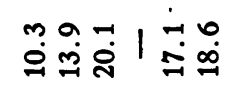 \\
\hline 車 & $\begin{array}{ll}0 & a \\
0 & 0\end{array}$ & $\hat{a}$ & कृष̃ & ษัญ์ & 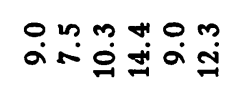 \\
\hline 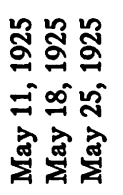 & 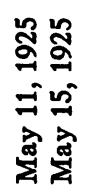 & 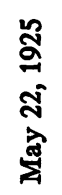 & 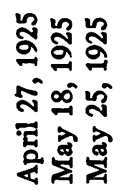 & 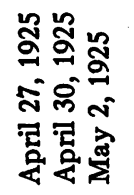 & 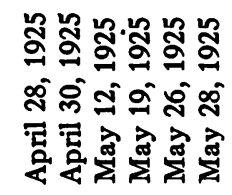 \\
\hline $\begin{array}{l}\dot{0} \\
\dot{4}\end{array}$ & $\dot{m}$ & $\stackrel{\leftrightarrow}{\stackrel{\leftrightarrow}{\curvearrowleft}}$ & $\dot{\varphi}$ & $\stackrel{\dot{B}}{\dot{B}}$ & ن \\
\hline$a$ & 옹 & $\Rightarrow$ & $=$ & $\stackrel{\infty}{\sim}$ & 9 \\
\hline
\end{tabular}


and when frequent measurements are made, high time-drop figures may appear in cases with normal initial surface tension. Finally, while the time-drop in dynes is greater at a dilution of $1: 1,000$ or $1: 5,000$ than at 1:100, one can, for comparative purposes, use the figures on 1:100 serum and thereby save time and glassware. It was only in cases 18 and 19, both nephrosis, that the time-drop in two hours exceeded 10 dynes in the case of 1:100 serum.

\section{GENERAL CONSIDERATIONS}

Low surface tension of the serum and edema. If one were to find a constant relationship between low surface tension of the serum and the presence of edema or a tendency to edema it would be tempting to explain edema as due to the effect of a surface-active substance. Its action would presumably be on the endothelial wall of the capillaries and would result in an alteration of permeability. Clausen (1) has been able to treat collodion membranes with the plasma or the urine or a surface-active, wax-like substance isolated from the urine of patients with parenchymatous nephritis with the result that the collodion membranes originally impermeable to protein become permeable. However, edema has not been experimentally produced by means of this surface-active substance. Furthermore, there is no clear evidence that an alteration in permeability of cellular membranes plays a rôle in the production of nephrotic transudates. The term "permeability" is used here only in reference to the passage of proteins through cell membranes. Possibly the edema fluid in acute glomerular nephritis is an exudate containing an appreciable amount of protein. This is not the case, however, in chronic nephrosis. Yet, it is in the latter that the lowest serum surface tension values are found.

In general, patients who have edema, or a strong tendency to edema, also have a lowered surface tension of the serum. However, there are a number of exceptions even in our relatively small group of cases. Case 17 (table 2 and chart 1), had normal surface tension in the presence of considerable edema. Case 9 (table 2 and chart 1) had almost normal surface tension on two occasions when edema was present. The development of edema in our cases is evidence of a marked tendency to edema because the patients had been on a salt-free diet and a restricted fluid intake for considerable periods of time. Case 
13 (table 2 and chart 1 ) with but slightly subnormal surface tension, showed at first no edema but had evidently a tendency to edema for he developed edema rapidly when allowed to take salt in his diet. The plasma protein and the plasma albumin figures in cases 17, 9 and 13 showed a far closer parallelism with the tendency to develop edema than did the surface tension values. It is difficult to draw any other conclusion from this fact than that drawn by Govaerts (2), - that low osmotic pressure of the plasma proteins is the constant accompaniment and important cause of non-cardiac edema in nephritis.

Low surface tension and the turbidity of the serum. The milky or creamy appearance of the serum, so characteristic and constant in many of the cases of renal disease, seems to be usually associated with low surface tension values. Case 13 , however, is a distinct exception. Milder grades of lowering of the surface tension may occur with perfectly clear serum. It is natural to think of the high total fat content of these creamy sera as being possibly responsible for the low surface tension.

The correlations between low plasma proteins, high plasma fats and low surface tension present a field for future study rather than for present conclusions. Probably some general metabolic disturbance underlies all three as a common etiological factor.

\section{SUMMARY}

In the three cases of apparently pure lipoid nephrosis observed, the surface tension of the serum was abnormally low. In the nephritics of other types it varied without apparent relation to the tendency to edema or to any other observed factor (see chart 1).

Tendency to non-cardiac edema in nephritis was found associated regularly with lowered plasma albumin content, but only irregularly with lowered serum surface tension.

\section{BIBLIOGRAPHY}

1. Clausen, S. W.: J. Biol. Chem., 1924, lix, p. xlv. Studies in Parenchymatous Nephritis.

2. Govaerts, P.: Bull. Acad. Roy. Med. Belgique, 1924, lv, 161. Recherches cliniques sur le rôle de la pression osmotiques des proteines du sang dans la pathogenie des oedemes et de l'hypertension arterielle. 
2a. Govaerts, P.: Compt. rend. Soc. Biol., 1925, xciii, 44 . Influence du Rapport Albumines-Globulines sur la Pression Osmotique des Proteines du Serum.

3. Kisch, and Remertz, O.: Internat. Zeit. phys. chem. Biol., 1914, i, 354.

4. Traube, J.: Internat. Zeit. phys. chem. Biol., 1914, i, 389.

5. Clausen, S. W.: Amer. Jour. Dis. Child., 1925, xxix, 594. Parenchymatous Nephritis. III. The Surface Tension of the Blood Serum.

6. du Nüoy, P. L.: Jour. Exp. Med., 1922, xxxv, 707. Surface Tension of Serum. II. Action of Time on the Surface Tension of Serum Solutions.

7. du Nüoy, P. L.: Jour. Gen. Physiol., 1918-1919, i, 521. A New Apparatus for Measuring Surface Tension.

8. du Nüoy, P. I.: Jour. Gen. Physiol; 1924, vi, 625. Surface Tension of Serum. XI. An improvement of the Technique for Measuring Surface Tension.

9. Van Slyke, D. D., Linder, G. C., Hiller, A., Leiter, L., and McIntosh, J. F.: Jour. Clin. Inv., 1926, ii, 255. The Excretion of Ammonia and Titratable Acid in Nephritis. 